\title{
Infant Depression: Nature Seeking Nurture
}

Paul V. Trad, MD

Cornell University Medical Center

Follow this and additional works at: https://jdc.jefferson.edu/jeffjpsychiatry

Part of the Psychiatry Commons

Let us know how access to this document benefits you

\section{Recommended Citation}

Trad, MD, Paul V. (1987) "Infant Depression: Nature Seeking Nurture," Jefferson Journal of Psychiatry. Vol. 5 : Iss. 1 , Article 4.

DOI: https://doi.org/10.29046/JJP.005.1.002

Available at: https://jdc.jefferson.edu/jeffjpsychiatry/vol5/iss1/4

This Article is brought to you for free and open access by the Jefferson Digital Commons. The Jefferson Digital Commons is a service of Thomas Jefferson University's Center for Teaching and Learning (CTL). The Commons is a showcase for Jefferson books and journals, peer-reviewed scholarly publications, unique historical collections from the University archives, and teaching tools. The Jefferson Digital Commons allows researchers and interested readers anywhere in the world to learn about and keep up to date with Jefferson scholarship. This article has been accepted for inclusion in Jefferson Journal of Psychiatry by an authorized administrator of the Jefferson Digital Commons. For more information, please contact: JeffersonDigitalCommons@jefferson.edu. 


\title{
Infant Depression: Nature Seeking Nurture
}

\author{
Paul V. Trad, M.D.
}

\section{INTRODUCTION}

Of the numerous clinical and theoretical problems confronting medicine today, infant depression represents an increasingly compelling and misunderstood concern (1). Early studies notwithstanding, the concept of infant depression remains in the embryonic and evolving stages of clarification. In studying infant depression, the clinical investigator is initially faced with the difficulty of devising a specific operational definition. Several definitional schemes have been proposed. The first advocates that depression is a proliferative idea that retains a concrete, immutable definition; another scheme argues that depressive affect, a key index of the disorder, is merely an illusory signal that masks the underlying process; still another approach views the diagnostic process embodied in clinical practice as being centripetally inclined, beginning its analysis on the perimeter of abnormality and moving inward. In this manner, a disorder can be inferred from the manifestations of a symptom complex. A reverse etiologic format may also be posited, in which the symptom complex can be interpreted as being derived from the disorder. In discussing infant depression, therefore, it is imperative that the clinician differentiate among these potential approaches and clarify whether depression is being viewed as a dysphoric mood, as an affective state, or as a syndrome.

As a dysphoric mood, depression is understood to refer to a pervasive and sustained dimension of feeling that is experienced internally and colors all of the individual's perceptions of the world. As an affect, depression refers to a cross-sectional view of a feeling-tone that may be a normal part of psycho-social development, a key symptom of a depressive disorder, or a noticeable symptom of a host of other disorders. The distinguishing feature of depression, in this instance, is that it is experienced as a discrete and transient phenomenon by the individual. Finally, as a syndrome, depression is identified by a cluster of various symptoms, (e.g., sleep disturbances, changes in appetite, anhedonia, and the like).

The evolution of the concept of childhood depression can be observed through four primary approaches. As distinct concepts have been formulated, each school of thought has created its own particular methodology to sustain or jettison arguments for the existence of depression in childhood.

Dr. Trad is a research fellow (PG-7) in the Laboratory of Developmental Processes, Payne Whitney Psychiatric Clinic, Cornell University Medical Center, New York, New York. This paper summarizes information from Dr. Trad's book entitled Infant and Childhood Depression: Developmental Factors, published by John Wiley and Sons, 1987. 
The "developmental symptomatology argument," the first school of thought, denied the existence of childhood depression altogether. The second, the "depressive equivalents argument," established the idea that an entity akin to childhood depression existed, but defined such pathology in terms of "depressive equivalents." The third school, referred to as the "epidemiological approach," accepted childhood depression as a separate and distinct clinical entity, and adopted an epidemiological mode of analysis for seeking a single etiology for childhood depression. The fourth school of thought accepted the idea of childhood depression, rejected the concept of depressive equivalents, and asserted that childhood depression manifests in virtually the same manner as in adults.

Ultimately, the views of those who advocated that childhood depression was a separate pathologic entity proved most persuasive, based on the available clinical data. However, while the concept of depression in children has been well accepted at this juncture, the notion of infant depression has remained less well-defined. Perhaps a similar progression of ideas will be observed in the development of a concept of infant depression. In the past, the existence of such a phenomenon has been strongly denied, based on the belief that infants are too immature developmentally to experience depression. Nevertheless, by painstakingly delineating the development of childhood depression, new knowledge may be gained and applied to research efforts in order that parallels may be drawn between childhood and infant depression, and that the specific contours of infant depression may be identified and predicted.

Remarkable changes in attitude and approach have occurred over the past 40 years with regard to the issue of childhood and infant depression. But we can still gain insight by examining how ostensibly depressed infants reacted 40 years ago and hypothesizing how such infants would react today in similarly deprived circumstances. In the $1940 \mathrm{~s}$, infants placed in hospital isolation units and denied human warmth exhibited a variety of clinical features associated with deprivation (3). In the 1980s, infants similarly denied warmth or security still provide abundant commentary on the effects of deprivation. Descriptions of the effects of such deprivation include the fact that the infant lies on the mattress hopeless and listless, indifferent to food, immobile, and despairing. The infant's eyes mutely implore why this abandonment has been imposed. Such infants seem sad and hopeless, bear dejected expressions, and display a withdrawn affect that is utterly unresponsive to environmental stimuli. Final evidence that this syndrome is wholly congruent with the depression encountered in adults or older children, however, has just begun to emerge in the literature. A more comprehensive view of depressive manifestations, therefore, is currently being formulated.

Although depression may be a discrete clinical entity in infants, the indices of the disorder may reveal itself differently in this young population. For example, depressive manifestations may change as they shift from apparently transitory developmental phenomena to clinically significant phenomena. 
Symptomatology alone may not sufficiently capture the ramifications of the disorder as it persists throughout the life span. To the clinical observer, the symptomatology may be discontinuous or inadequate, and the sporadic appearance of depressive-like affect may be difficult to trace from its initial appearance. In infancy, therefore, the ambiguous boundaries between depression as a discrete affect and a generalized syndrome need to be more incisively demarcated. Depression as an affect may be an isolated manifestation (e.g., transient sad facial expression, as listed in the DSM-III [2]) that does not warrant the diagnosis of full-fledged depression.

Significant in this regard is whether the investigator uses objective or subjective criteria in assessing the infant. Infancy, by its nature, forces the clinician to rely strongly on objective criteria such as direct observation of facial expression and behavior, in sharp contrast to the situation posed by adults or children, who are able to offer clinicians their subjective impressions via verbal communication. Nevertheless, it must be appreciated that even when assessing such ostensibly objective measures as infant facial expression, the clinician may introduce an element of subjective interpretation.

Several questions are raised by this discussion. Do the diagnostic criteria of DSM-III capture the broad spectrum of depression manifested during childhood and infancy? Moreover, do these criteria distinguish between depression as a dysphoric mood, as a syndrome, and as an affect? What elements in the adult diagnostic criteria of DSM-III may be applied to detect the various domains of depression in infancy? While the study of infant depression may be able to borrow methodologies developed for the study of childhood depression as a syndrome (e.g., biological markers), nevertheless, original methodologies designed to study depression as an affect in infants are still sorely needed. When developmentally approached, such tailored means will help clarify the etiology as well as the appropriate treatment of these phenomena in the infant population.

\section{A NEW MODEL: THE DEVELOPMENTAL PERSPECTIVE}

Although a review of the diagnostic criteria for both adult and infant depression reveals that some symptomatic and behavioral aberrations are shared by both populations, other manifestations appear unique in infant depressive pathology. For example, in infancy depressive-like affects may be systematically debilitating in and of themselves, while in late childhood it is more likely that a cluster of symptoms is experienced as overwhelming. For the purposes of this paper, infancy is defined as the chronological period between birth and two years of age.

Although the symptomatology is often too intermittent in infants to define congruencies between infant and adult depression, there are two other methods of linking depressive pathology throughout the life cycle. One is to chart the continuities and discontinuities of the physiological, behavioral, emotional, 
cognitive, biochemical, and psychological correlates for the depressive affect in order to delineate a depressive syndrome; the other way is to distinguish common biological markers that correlate directly with depressive disorder. Each of these methods can indicate developmental antecedents that aid not only in diagnosing depression in infancy, but also in predicting depression throughout life (1).

What are the preconditions for the development of infant depression? Is an infant equipped to develop the same clinical manifestations as the adult? How do symptoms mushroom from transitory developmental phenomena that are unreliable over time, to clinically significant phenomena that remain reliable with the passage of time? Might the infant be more resistant than the adult to developing depression? If so, what factors determine the infant's threshold to such psychopathology? Can the competence with which the infant expresses different affects be measured? Most significantly, are there any markers for depression idiosyncratic to infancy?

Developmental psychopathologists recognize that individuals meet developmental challenges with different biological and temperamental constitutions and that both inborn characteristics, as well as environmental variables, influence development. Their model adopts neither the "nature" nor the "nurture" bias in the timeless debate that has tended to oversimplify a complex interaction between individuals and their environments. As Sroufe and Rutter (4) argue, "only by understanding the nature of the developmental processwith progressive transformation and reorganization of behavior as the developing organism continually transacts with the environment-is it possible to understand the complex links between early adaptation and later disorder" (p. 20).

Clearly, depression represents the outgrowth of a complex set of interactions involving constitutional elements, such as genetic and temperamental endowment, as well as the products of affective and cognitive development. This paper examines depression in early life as a function of the interplay among these variables, as specifically manifested through attachment and self-representation behaviors. These behaviors have been selected for a number of reasons. First, disorder in each behavior has been independently correlated with adult depressive symptomatology, as an interpretive reading of DSM-III reveals. Second, these behaviors first manifest in early infancy, and establish patterns of adaptation or maladaptation for later life. Third, as we shall see, these behaviors are mutually reinforcing. Finally, attachment and self-representation manifestations have strong predictive validity.

\section{PREDICTIVE VALIDITY}

Needless to say, theories gain credibility in many ways. In the sciences, predictive power is weighed heavily in the determination of theoretical validity. Testing a theory, therefore, requires an evaluation of its predictive power. 
Developmental psychopathology is still a recent approach, wrestling with numerous unresolved theoretical and methodological issues concerning its ability to predict adaptation and maladaptation from early functioning. Indeed, in the course of its early refinement, developmental psychopathology has encountered several challenges to its predictive validity.

Such challenges are healthy for the evolution and application of a theory. They force researchers to articulate assumptions and implications more clearly, as well as to assess the strengths and weaknesses of the theory. In fact, when correlating findings on the environmental risk factors cited to substantiate their theory, developmental psychopathologists have modified hypotheses to reflect new evidence on the relationships between intrapsychic experience and risk factors and the implications of these relationships for predictability. It is important to keep in mind that environmental influences, anatomic factors, and intrapsychic subjective experience congeal in the infant as separate analytic expressions of the unitary, indivisible, developmental processes of the organism.

Most explanations for the seeming lack of continuity in developmental phenomena rely on the unpredictability of environmental factors. Environmentalists, such as Kagan (5) assert that many psychological states are products of the vagaries of the environment which can be expected to result in discontinuities rather than continuities. Taking this proposition a step further, Kagan implies that the behaviors typical of one stage of development, whether pathological or not, do not lead inexorably to similar behaviors at later stages. Consequently, characteristics of a later age are not dependent upon, nor derivative of, experiences of an earlier stage. If environment, rather than early patterns of functioning, governs the course of development, this hypothesis suggests that deviance may not only appear, but also may disappear abruptly. Indeed, research has demonstrated that environment can not only cause disorder, but can ameliorate it (6-9). According to this line of thought, environment operates in conjunction with the body's own homeostatic tendencies and can reverse the impact of early deficits, thereby creating discontinuities in the normal course of development. Specific developmental deficits-in terms of depression such deficits include failure to develop secure attachments and to represent oneself adaptively — will thus retain their long-term predictive strength.

\section{EMPIRICAL SUPPORT FOR THE DEVELOPMENTAL MODEL IN THE STUDY OF DEPRESSION}

No theoretical construct predicts all phenomena equally well. This is certainly true of the developmental model. Although many of the theorists most enthusiastic about the breadth of its explanatory power have narrowed their focus somewhat, developmental psychopathology has weathered initial criticism well.

When discussing predictability, it is important to remember that we are 
concerned with two basic dimensions of predictability-inter-variable and temporal - as well as with the relationship between these dimensions. Temporal predictability refers to the stability of a variable (e.g., attachment behavior), from one chronological point to another. Inter-variable predictability denotes consistency in the influence of one variable upon another. The relationship between temperament factors and attachment behaviors might be one example of this kind of predictability. Early attempts to apply developmental theory to the prediction of various disorders have tended to focus narrowly on one dimension or the other. As this paper demonstrates, in the context of depression, stability exists not so much in any single factor viewed in isolation, as much as within the system of interaction between variables. Relationships between two variables can, in this fashion, "borrow" stability from predictable relationships to other variables. What remains stable is the overall adaptiveness or maladaptiveness of the individual. This view derives from the transactional model described by Sameroff (8). It is part of the researcher's task to identify the dimensions of predictability that unite the separate variables together in a continuously operative, predictive system. In fact, research on many facets of affective development reveals a comparatively high level of predictiveness.

In a review of the literature, Rutter (10) cites growing evidence indicating that the early development of skills for coping with adversity will affect later success in mastering environmental stress. Other studies also support the notion of continuities in affective development. In a longitudinal study of 3- to 5 -year-olds, Lerner (11) found that the 20 children with the greatest overall affective disturbance as preschoolers had the greatest risk of developing psychiatric disorders by the time they were teenagers. Early behavioral disorders, such as aggressiveness, withdrawal, and hyperactivity, predicted many affective disorders. Interestingly, however, these disorders did not predict psychotic disorders.

\section{TEMPERAMENT, ATTACHMENT, AND SELF-DEVELOPMENT CHARACTERISTICS PREDICTIVE OF STABILITY}

The results of several studies have suggested that the DSM-III criteria for depression are appropriate for children $(12,13)$ and infants (14). The cluster of symptoms described by DSM-III is similar to that reported in 1946 by Spitz and Wolf (3), who observed young children separated from their mothers. Investigators have generally reported that depressive-like stages in young children are typified by clusters of symptoms which include sadness, affectlessness (sometimes manifested as anhedonia, loss of interest, or withdrawal), and irritability.

Temperament, attachment, and self-development studies have scored behaviors that are expressive of affective states such as sadness, affectlessness, and irritability. The New York Longitudinal Study $(13,15)$ which many consider the paramount study of temperament, identified nine dimensions indicative of temperamental predisposition. These dimensions can also be used as parameters 
underscoring affective states. One dimension, "intensity of reaction," measures both negative and positive aspects of this phenomenon which may correspond to the symptom of affectlessness. A negative score on another temperamental dimension, "quality of mood," may be viewed as describing the negative affective sign of depression. Evidence of behavioral irritability may correspond to a low score on the dimension "threshold of responsiveness."

The "strange situation procedure" (16), which is the most widely accepted paradigm for assessing security of attachment, specifically measures the various affective responses displayed by the infant during separation and reunion episodes with the caregiver. The strange situation also records affective displays occurring between the infant and a stranger. By following this format, the strange situation becomes instrumental in revealing degrees of the infant's affectlessness, irritability, and sadness during interaction with the parent.

Since temperament and attachment measures seem to correlate with affective states in the infant, these scales may relate to infant depression. However, in recent years, debate has focused on the way in which these constructs are related, and upon whether temperament and attachment are actually describing the same processes. Additionally, researchers investigating both concepts have attempted to predict later behavior from earlier testing of either temperament or attachment (13,17-19). Most temperament theorists maintain that temperament pertains to individual differences, with early, possibly genetic characteristics in the infant contributing significantly to later development in adaptive and social functioning. The concept of attachment, on the other hand, is interpreted as a relational construct, which attempts to predict social functioning from early relationships between the infant and its primary caregiver (or caregivers).

Distinguishing the effects of early caregiving from the effects of infant individual differences can be problematic. Given the generally accepted dictum that temperament expressions are affected by environmental factors and that expressions of attachment are affected by constitutional infant factors (20-23), it is still desirable to discriminate the different factors contributing to behavior and to the genesis of a particular disorder such as depression. Rothbart has warned that, "unless we have strong prospective support for predictability from the early years, the 'at risk' category (for developing later behavior disorders) may not be warranted"' $(24$, p. 38$)$.

Temperamental Stability. Temperamental stability, both over time and in relation to depression, has been the focus of heated debate among researchers. Thirty years of longitudinal research in the New York Longitudinal Study (NYLS) (1956-present) suggests that specific categories of temperament display little long-term predictability. However, Thomas and Chess, the pioneers of this study, document considerable continuity in clusters of traits followed through childhood. They found that the nine dimensions of temperament they isolated in infants tended to cluster into three groups: "difficult," "easy," and "slow to warm up." These broad categories showed greater stability than the individual measures of which they were comprised (15). 
Not surprisingly, individual temperament categories, which themselves are less stable over time than composite profiles, do not predict behavioral outcome as reliably as composite temperament profiles. In fact, data culled from NYLS casts doubt upon the value of the isolated temperament dimension of "mood" for predicting the development of depression. In particular, mood did not appear to correlate with depression among the six depressives that Thomas and Chess identified in the study. Only one of the two children diagnosed as a recurrent major depressive exhibited a negative mood during the first five years of life. Of the three cases with dysthymic disorders, only one showed a marked and consistent tendency toward negative mood early in life. These findings should be interpreted with caution, as the authors note, due to the small size of the sample. Furthermore, the dimension of mood, which is measured only as negative or positive, may, in fact, be too global to capture the subtleties of affect that signal depression.

In a review of the literature, Plomin (26) observes that composite temperament profiles have succeeded in predicting a variety of behaviors exhibited both concurrently and later in life, including mother-child interaction, school achievement, and adjustment disorders. Research using temperament profiles to predict long-term behavioral outcomes is still limited, however, and the study of depression suffers from this shortage of data. We can draw strong inferences from studies using other indices, such as conduct, to predict depression. Puig-Antich (27), for example, found that over one-third of the patients at the Child Depression Clinic of the New York State Psychiatric Institute met DSM-III criteria for conduct disorder. Although only long-term study can establish the long-term predictiveness of prepubertal conduct disorders for other disorders, including depression and antisocial personality, Puig-Antich expects that a substantial proportion of these young children will suffer from one of the depressive spectrum disorders as well.

The ability to use broad temperament profiles to predict behaviors concurrently and at future points implies that although specific traits may not remain stable, broad profiles will endure. This stability has been demonstrated by some researchers. Peters-Main and Wachs (28) examined specific categories as well as broad dimensions of temperament in infants under one year old and found stronger correlations between broad dimensions of temperament, such as behavioral organization and temperamental ease. In a multi-method study (29), it was found that individual differences in temperament remained stable not only from 18 to 24 months of age, but also across different settings as well. Again, composite temperament measures derived from multiple discrete behaviors appear to show greater predictability over time than do the specific behaviors.

Attachment Behavior Stability. In contrast to the uncertainties surrounding temperamental manifestations, attachment behavior reveals a great deal of stability over time. For example, Antonucci and Levitt (30) observed infants on two separate occasions, once at 7 months and once at 13 months. They used the 
Ainsworth strange situation to measure attachment security in the 13-month-old infants, and used an analogous separation and reunion sequence to measure attachment when the infants were younger. On the basis of these measurements, the researchers concluded that infants classified as securely attached at 7 months remained securely attached at 13 months. Their findings support Waters (31), who showed that 48 of 50 one year olds studied remained in the same Ainsworth classification category (securely attached, anxious-avoidant, or anxious-resistant) when evaluated again at 18 months old.

Self-Representation Stability. The predictability of self-representation from attachment security is particularly significant in light of the findings suggesting stability in early attachment behavior. In an important recent study, SchneiderRosen and Cicchetti (32) explored the relationship between self-representation and attachment, and found that self-recognition appears to correlate with secure attachment. Analysis of 37 infants, aged 19 months, revealed that of those who were able to recognize themselves using the standard rouge and mirror paradigm, almost three times as many (73 percent) were securely attached than were insecurely attached (27 percent). Several years earlier, Arend, Gove, and Sroufe (33) discerned a relationship between attachment security at 18 months, autonomous functioning at 2 years, and ego-control and resiliency at 4 to 5 years old. From a developmental perspective, the significance of these relationships lies in the translation of competence and adaptiveness in attaining one developmental milestone-attachment security-into success in reaching anotherself-representation.

Maternal Characteristics that Predict Stability. Egeland and Farber (34) have noted that both maternal and environmental factors contribute to stability or change in attachment classification. Their sample encompassed a range of maternal characteristics considered to be high-risk for infant adaptation. The mothers ranged in age from 12 to 37,62 percent of the mothers were single, and 86 percent of the pregnancies were unplanned. Forty percent of the mothers had not graduated from college by the time their infants were born.

Dyads who changed from secure to avoidant attachment were characterized by high ratings for aggression and suspiciousness as manifested by the mothers. Also, in comparison with those mothers whose infants remained securely attached, these mothers were assessed to be lower on scales of social desirability. In contrast, babies who changed from avoidant attachment to secure attachment had mothers who responded to, spoke to, and looked at them more, and who were more effective in responding to infant crying than mothers of infants who remained avoidant at both assessments. In addition to the maternal contributing factors mentioned above, mother-infant separation was presumed to account for changes from securely attached to anxious-avoidant $(\mathrm{N}=3)$, as well as for stability in 7 anxious-resistant infants. Separation in both groups of infants occurred anytime between birth and 18 months.

In a study by Gaensbauer et al. (35) in which the infants of manic-depressive parents were followed longitudinally, the authors reported the following 
changes in the infants' attachment classifications: During the first observation, the probands $(\mathrm{N}=7)$ and the control group $(\mathrm{N}=7)$ had the same breakdown of attachment groups. Five were classified as securely attached and two as avoidant in each group. When they were re-evaluated at 18 months, six of the probands were classified as avoidant and only one was classified as securely attached. In the control group, four were classified as securely attached, two as avoidant, and one as insecurely attached. The authors concluded that infants with at least one manic-depressive parent showed a greater tendency for avoidant withdrawal from their mothers, and that differences in infant affective regulation appeared to be salient between 12 and 18 months of age.

The effects of maternal depression on attachment behavior have also been studied by Radke-Yarrow et al. (35). These researchers observed children who ranged in age from 16 to 44 months. Fourteen children out of 99 in the total sample were offspring of mothers with bipolar depressive disorder; 42 children in the sample had mothers with major unipolar depression; 12 had mothers with minor depression; and 31 children had mothers with no history of affective illness. Infant attachment behavior was assessed along with direct observation of maternal affective states.

Insecure attachment was relatively frequent in families with major affective disorders: 48 percent of the unipolar and 79 percent of the bipolar offspring were classified as insecurely attached, while, in contrast, the normal group and the minor depression group had 25 percent and 30 percent respectively of infants who were insecurely attached.

Radke-Yarrow et al. noted a fourth category of attachment behavior, which they designated avoidant-resistant. These infants $(N=20)$ showed moderate to high avoidance and moderate to high resistance during reunion episodes. Interestingly, the mothers of these infants had histories indicative of a significantly higher incidence of depression. As noted from the study, maternal status predicted attachment classification. The authors noted that maternal emotional expression, displayed in interactions with infants, also predicted patterns of attachment. That is, the mothers of insecurely attached infants expressed more negative and less positive emotional states.

Maziade et al. (37) have found clear correlations between temperamentally difficult children at age 7 years and other psychopathologic diagnoses at age 12 years (e.g., oppositional disorder and deficit disorders).

Environmental Characteristics that Predict Stability. From the above cited studies, we have identified examples of both infant and maternal factors that predict stability of individual differences and psychopathology. However, in recent years there has been an increasing recognition that certain environmental factors may also precipitate depression.

Among the factors that have been identified, social support is of striking importance. Crockenberg (38) correlated neonatal temperament measures and strange situation classifications for 48 infants with the levels of social support as perceived by the mothers. This researcher found that low social support was 
associated with insecure attachment, but only in those infants who showed high temperamental irritability on the behavioral assessments. Another correlation was shown between maternal unresponsiveness and insecure attachment, but only when social support was low. This study provides evidence that an irritable infant raised by a mother who experiences low social support is prone to develop insecure attachment. However, the findings are ambiguous due to the subjective nature of the measure of social support. It may be that the mother's unresponsiveness and her perception of her support are derivative of yet another variable and are unrelated to objective measures of social support. The study does, however, clearly indicate that maternal factors contribute to insecure attachment.

In the study referred to earlier by Egeland and Farber (39), the authors observed that stressful living arrangements were a contributing factor in infants who changed attachment classifications from secure to resistant. Seventy percent of their sample were children of single parents. Stressful living arrangements were also a factor when comparing infants who remained avoidant at 12 and 18 months, with those who changed from avoidant to secure attachment. These authors concluded, in accord with Crockenberg, that a developmentally delayed infant from a lower socioeconomic background may be at greater risk for forming an anxious-resistant attachment to the caregiver.

Another example of the effects the environment may impose on mother and infant is provided by a Radke-Yarrow et al. study (36) involving the offspring of families with major maternal depression. Anxious attachment was identified in seven out of eight of the subjects where no paternal figure was present. That is, mothers with a major affective disorder who were without a husband in the household were noted to be at a higher risk for developing insecure mother-infant attachment.

Discussion. Historically, temperament studies have focused on endogenous characteristics, while attachment studies have emphasized the environmental contributors to infant behavior. As the above studies demonstrate, the current trend is to adopt an interactive analysis. As temperament researcher Robert Plomin (21) comments, it is a "truism" that behavior takes place in a social and environmental context. No one currently would deny that both infant and environment contribute to the expression of genetic and evolutionarily determined behavior. The exact boundaries of determinance are unlikely to be defined, of course. It is important to keep in mind that all constructs are merely separate descriptions of a unitary process; any contradictions in theory are resolved in the reality of a living, developing child. With this unified approach in mind, we can proceed to examine the usefulness of the attachment and temperament constructs in defining and predicting early childhood depression and depressive symptoms.

Only by assessing and integrating all of the salient factors noted above can the investigator uncover and detect the infant's affective states. Once these contributing factors are discerned, what was once known as "depressive equiva- 
lents" might interchangeably be referred to as "developmental equivalents." Further research is needed to clarify the issue of depression in infancy, not only as an identifiable pathological entity, but also as a disorder whose manifestations are revealed primarily through the display of discordant affects.

\section{DEVELOPING A CONCEPT OF INFANT DEPRESSION}

All socio-cultural groups share the ability to consensually validate expressions of basic human emotions. In interpersonal terms, facial expressions provide us with important clues concerning the qualitative meaning of social interactions.

Darwin emphasized the value of observing facial expression as a form of emotional communication in his 1877 "Biographical Sketch of an Infant" (39). Observing one of his children, Darwin arrived at a crude classification of the development of affective states. He found that pleasurable sensations were associated with infant sucking and gazing at the mother, and that smiling appeared in these situations at 45 days. Consciously affectionate behaviors were seen at two months and sadness manifested at six months. Labelling fear as one of the earliest emotions, Darwin observed fear, followed by crying, when his child was only a few days old. Similarly, moral sense, shame, and anger appeared after the first year, and shyness after the second.

Within the past few decades, several investigators have begun to particularize affective responses more discretely. These responses impart meaning and significance to the internal and external events of an individual's life; they also affect the organism's response to these events. Their function is ultimately one of adaptation-to help the individual cope with ever-changing internal and external environments. More recently, in an imitation paradigm for happy, sad, and surprised facial expressions, Field (40) found that neonates with a mean age of 72 hours were able to discriminate between these facial expressions. The researcher hypothesized that these imitations may be released by an innate ability to compare the sensory information of visually perceived expressions with proprioceptive feedback of physiologic movement. This study reveals the role of affect even very early in life.

The concept of anaclitic depression or depression in infancy was first elaborated upon by Spitz in 1946 (3). Freud, in 1914 (41), first used the term anaclitic to mean "leaning toward a need-gratification essential for survival." Spitz adopted the term "anaclitic depression," for a clinical syndrome indicating a condition of partial emotional deprivation observed in infants. Although the term can describe a particular depressive phenomenology, it does little to finely discriminate the sources of its etiology. Spitz recognized that after six months, separation from the maternal object led to a grief reaction in the infant, if the previous relationship had been satisfactory. Infants experiencing grief reactions became sad, weepy, and apathetic, and developed immobile facial expressions with a distant look. They reacted slowly to stimuli, demonstrated retarded 
movements, suffered from anorexia and insomnia, and lacked the normally expected infant mobility. Spitz characterized an infant's negative reaction to the primary caregiver as a three-part response: protest, rejection, and withdrawal. Moreover, he found numerous infant parallels to adult depression, including listlessness, immobility, passivity, loss of appetite, apathy, weight loss, sleep disorders, crying, affectlessness, and withdrawal. These infants were diagnosed as being depressed, since their behavior bore such a striking resemblance to adult depressed behavior.

At birth, to bring about and enhance strong attachment, the infant's armamentarium includes sucking, grabbing/holding, crying in a variety of pitches and levels of loudness and urgency, and smiling. These behavioral maneuvers reliably seduce and hold the ministrations of the primary caregiver or parent. Moreover, these behaviors seem to facilitate the infant's need to engage in such survival behavior as eating and feeding.

Robertson and Bowlby (42) discerned three distinct stages in the reaction of infants and children to maternal separation. Initially, protest is observed, characterized by high agitation and attempts to return to the mother; the subsequent despair stage is marked by weeping and reduced activity; and the final detachment phase features a general withdrawal from activity and a rejection of the mother's attempts to reestablish a relationship.

Depression in infancy, or similar reactions indicative of psychopathology, has been noted in nonhuman primates (43). Kaufman et al. observed that the Rhesus Macaque monkey, raised in social isolation from birth to 12 months and then tested socially, tends to spend most of its time self-mouthing and rocking. Its behavior is generally marked by social withdrawal.

Prior research reflects the problem of correctly identifying so-called "disorder" in infants. The problem is a lack of sensitive diagnostic tools and thus, no more than a limited access to infant experience. The difficulty in isolating depression as a syndrome and the inadequacy of the research criteria are demonstrated in a study conducted by Poznanski and Zrull (44). They reviewed the charts of 1,788 children seen at a child psychiatric hospital and found only one child under the age of five who might possibly have fit the clinical criteria for depression. Like the third school of thought (discussed earlier) identified in the study of childhood depression, these investigators adopted an epidemiological or single-factor approach which, in retrospect, seems over exclusive.

In a study by Kashani (45), 100 children (67 boys, 33 girls; ages $1-6$ years old) were referred to a development unit for developmental, behavioral, or emotional problems. Of the 100, Kashani found only four-two girls, two boys - who met the DSM-III criteria for depressive disorders. Only one girl had a definite diagnosis of major depressive disorder. Of the remaining three, one had definite, and two had possible diagnoses of dysthymic disorder. Prevalence of all types of depressive disorders, therefore, was 4 percent, using the DSM-III guidelines.

Gaensbauer (14) described the clinical entity of anaclitic depression in a 
31/2-month-old infant. This researcher used a multifactorial approach, taking into account more inclusive criteria, and found that infant depression as a separate clinical entity can be seen not only at six months of age, but as early as $3 \frac{1}{2}$ months of age as well. Gaensbauer used the more inclusive approach in studying the correlates for affect, as well as the correlates for the syndrome. Studies must be developed, therefore, to take cognitive, affective, and affiliative developmental lines into consideration, and to cluster these correlates. In the study of depression as a childhood syndrome, the correlates were clustered around the syndrome; in the study of depression as an affect in infancy, the correlates must similarly be clustered independently around each affect.

\section{CONCLUSION}

Future Directions in the Need for Improved Research and Classification Methods. Given the plethora of unanswered questions about how frequently depression occurs at different ages and what constitutes depressive symptomatology over the course of time, it is not surprising that research to date offers only limited assistance as to whether depression in early life predicts depression in adulthood. Rutter and Garmezy (46) present several seemingly contradictory pieces of evidence in their review of the literature. On the one hand, most adult depressives studied longitudinally do not report depression as children. On the other hand, depression seems to show stronger chronological continuity than all other disorders except obsessive-compulsive disorders. Among most depressed children who continue to have psychiatric conditions in adulthood, depression constitutes part of their clinical picture. Notably, however, depression fits into a broader constellation of symptoms and rarely represent the primary diagnosis.

These data seem to suggest that we direct our investigations not toward diagnostic categories such as depression per se, but toward the variety of age-specific maladaptive behaviors that evolve and interact over time, ultimately determining an individual's vulnerability to depression. Biological investigations into the nature of depression have followed a similar course, culminating in the permissive amine hypothesis. This theory postulates that abnormally low levels of brain serotonin increase an individual's vulnerability to depression.

If links between affective symptoms from infancy to adulthood demonstrate more stability than do clinical diagnoses, then there is merit in Sroufe and Rutter's (4) recommendation that we adopt a different level of analysis and focus on adaptational failures, such as poor peer relations, as well as both conduct and affect disturbances. Consideration of both types of deviance is critical, as Sroufe and Rutter note,

... it is unlikely that the specific affect aberration, in the absence of the broader adaptational failure, would predict adult depression. Rather, presence of both the general, age-related adaptational failure and the particular pattern of maladaptation are required for predicting adult disorder (p. 27). 
Predicting adult depression from childhood depression is thus subject to the same potential pitfalls as predictions of other disorders. Reliability exists not only in the method used to measure continuity, but also more importantly in the criteria used to identify child and adult depressives. Since depressive behaviors are clearly not isomorphic over time, researchers will have to examine the interaction of different processes, such as reactions to separations and the control and expression of feelings, to know whether childhood depression unfolds into adult depression.

Classifying in a Developmental Framework. Paradoxically, the developmental psychopathologist's perspective arises from, yet is most hampered by, the lack of a classification scheme capable of accounting for the many factors which may make pathological conditions express themselves differently at different points in development. By ignoring developmental considerations, most classification schemes have applied criteria derived from experience with adults directly to children. However, with the particularly rapid pace of change that occurs during childhood, the search for adult traits in diagnosing childhood disorders may prove misleading. Certain forms of cognitive, physiological, and emotional maturity are prerequisites for the emergence of particular types of symptoms (47). Therefore, some symptoms characterizing the adult form of a disorder may not appear in the childhood version of the disorder. The absence of the adult symptom, therefore, should not lead to the conclusion that psychopathology does not exist in the child. Researchers, however, have often fallen into this trap. Failure to detect the adult characteristics in children has led to the conclusion that continuity does not exist. Moreover, the difficulty in assessing adult-like qualities at an early age has led many researchers to the specious conclusion that a particular form of adult pathology has no childhood antecedents. On the opposite side of the same coin, many apparent later life adjustments from early psychopathology may not represent adjustments at all, but rather failures of existing methods to detect pathology as it evolves through developmental periods.

These theoretical problems have heightened interest in refining classification methods to address developmental considerations. Although some authors have rejected classification of childhood disorders altogether because of the constant changes that occur during childhood, Tanguay (47) and Garber (48) still maintain that for children, a developmentally-oriented classification scheme would provide greater insight into the cause of psychopathology than does the symptomatic approach of DSM-III. Garber contends that a classification scheme focusing on methods of adaptation is essential for identifying and treating psychopthology in children. She argues that:

...the natural course and prognosis of a disorder in childhood should be assessed independently of its continuity with adult psychopathology ... and classification of developmental psychopathology should have a way of capturing the process of change and development that children undergo. It should not be limited to the classifica- 
tion of isolated and static behaviors and attributes. Rather, some notion of the coherence of the individual in terms of his or her manner of organizing and integrating information and experiences needs to be included in a developmental system of classification.

Garber's scheme is necessarily multidimensional and incorporates expectations for age, sex, developmental phase, level of functioning, environmental, and familial and cultural influences. A gradual adoption of Garber's stance is reflected in the evolutional steps toward defining infant and childhood depression-from the early concept that depression, as a syndrome analogous to that found in adults, does not exist in childhood, to the currently prevailing view that starts with an understanding of adult depression and posits a similar childhood phenomenon that can be studied in the same way by means of a multifactorial approach. Using DSM-III as a framework, researchers hope to incorporate the specific symptomatology for infant and childhood depression and depressivelike phenomena. Their aim is to provide a more precise developmental framework for the phenotypic changes that coincide with the development of depression. There is also a need to define more clearly whether these milestones are co-occurring with depression or only with some sub-types of depression.

The urgency for developing such a classification scheme for childhood depression is underscored in a recent study by Poznanski et al. (49) who compared the results of four different sets of diagnostic criteria in detecting depression among children 6 to 12 years old. Although the four sets of criteria-Research Diagnostic Criteria (RDC), DSM-III, Poznanski, and Weinberg-concurred in most cases about the diagnosis, in cases of disagreement, the differences lay in essential rather than qualifying criteria. Moreover, the particular criterion-the determination of dysphoric mood-that accounted for most of the variance has a significant developmental dimension, as recognized in DSM-III's acceptance of nonverbal rating of affect in children under 6 years old.

Symptomatology relating to DSM-III criteria for depressive disorders is shown by Goldsmith and Campos (50) to be related to the affective expression of dimensions of temperament. Almost all of the DSM-III symptoms can be accommodated by one or more temperament dimensions. However, there are, as yet, no adequate descriptions of common temperament clusters or typologies which relate to depression. The typology of the "difficult" temperament has been shown to correlate more strongly with behavioral disorder than either the "easy" or the "slow-to-warm-up" typologies, but the risk is not specifically related to depression. One significant fact, although found in too small a sample to be statistically significant, is that both cases of major depression found by the NYLS had a history of depressive illness in their families. This finding would lead one to suspect that, for cases of primary depression, hereditary factors are involved. In addition, it would be interesting to see the results of more research into such biologic factors as neuroendocrinologic parameters in infants. 
The attachment and self constructs have also been fruitful in producing etiologic scenarios for infants at risk for depression. The behavior of insecurely attached infants, both avoidant and anxious, shares many characteristics with the symptomatology of depression. Also, the literature on children undergoing separation from their caregivers is filled with poignant descriptions of depressive-like phenomena. Lastly, the studies of Radke-Yarrow et al. (36), and Belsky, Rovine, and Taylor (51) on the children of depressive parents indicate a clear correlation between maternal and child depression.

In sum, this paper has advocated a developmental approach, which combines data acquired from the areas of temperament and attachment studies, for deciphering both the etiology and the most frequent manifestations of depression encountered during infancy. It is contended that only by adopting such an integrated method can a full appreciation of depression during the early years of life be achieved.

\section{REFERENCES}

1. Trad PV: Infant and Childhood Depression, Developmental Factors. New York, John Wiley \& Sons, 1987

2. American Psychiatric Association, Diagnostic and Statistical Manual of Mental Disorders, 3rd ed., Washington, DC.. American Psychiatric Association, 1980

3. Spitz RA, Wolf KM: Anaclitic depression. Psychoanal Study Child 2:313-342, 1946

4. Sroufe LA, Rutter M: The domain of developmental psychology. Child Dev 55:1729,1984

5. Kagan L: Retrieval difficulty in reading disability. Top Learning and Learning Disability 3:75-83, 1983

6. Garmezy N, and Rutter M: Stress, Coping, and Development in Children. New York, McGraw-Hill, 1983

7. Garmezy N, Masten AS, Tellegen A: The study of stress and competence in children: a building block for developmental psychopathology. Child Dev 55:97-111, 1984

8. Sameroff AJ: Early influences on development: fact or fancy? Merrill-Palmer $Q$ 21:267-294, 1975

9. Sameroff AJ, Chandler MJ: Reproductive risk and the continuum of caretaking casualty. Psychiatry Update 3:197-244, 1984

10. Rutter M: Stress, coping, and development: some issues and some questions, in Stress, Coping, and Development in Children, Edited by Garmezy N, Rutter M, et al. McGraw-Hill, 1983

11. Lerner JA, Inui TS, Trupin EW, Douglas E: Preschool behavior can predict future psychiatric disorders.J Amer Acad Child Psychiatry 24:42-48, 1985

12. Earls F: Application of DSM-III in an epidemiological study of preschool children. Amer J Psychiatry 139:242-243, 1982

13. Chess S, Thomas A: Origins and Evolution of Behavior Disorders: From Infancy to Adult Life. New York, Brunner/Mazel, 1984

14. Gaensbauer TJ, Harmon RJ, Mrazak D: Affective behavior patterns in abused and/or neglected infants, in Psychological Approaches to Prevention of Child 
Abuse. Edited by Frude N. London, Batesford Academic and Educational Ltd., 1980

15. Thomas A, Chess S, Birch HG, Hertzig ME, Korn S: Behavioral Individuality in Early Childhood. New York, New York University Press, 1963

16. Ainsworth MDS, Wittig BA: Attachment and exploration behavior of one-year-olds in a strange-situation. Determinants of Infant Behavior 4:113-136, 1969

17. Ainsworth MDS, Blehar MC, Waters E, Wall S: Patterns of Attachment: A Psychological Study of the Strange Situation. Hillside, NJ, Erlbaum, 1978

18. Sroufe LA, Waters E: Attachment as an organizational construct. Child Dev 48:11841199,1977

19. Main M, Weston DR: The quality of the toddler's relationship to mother and to father: related to conflict behavior and readiness to establish new relationships. Child Dev 52:932-940, 1981

20. Sroufe LA: Attachment classification from the perspective of infant-caregiver relationships and infant temperament. Child Dev 56:1-14, 1985

21. Plomin R: Childhood temperament. Adv Clin Child Psychol 6:45-92, 1983

22. Campos JJ, Barrett K, Lamb ME, Goldsmith ME, Stenberg C: Socioemotional development, in Handbook of Child Psychology, vol 2: Infancy and Developmental Psychobiology, Edited by Haith MM, Campos JJ. New York, John Wiley \& Sons, 1983

23. Bates JE, Maslin CA, Frankel KA: Attachment and security, mother-child interaction, and temperament as predictors of behavior-problem ratings at age three years, in Growing Points of Attachment Theory and Research. Edited by Bretherton I, Waters E. Monographs of the society for research and child development 50:167-193, 1985

24. Rothbart MK, Derryberry D: Theoretical issues in temperament, in Developmental Disabilities: Theory, Assessment, and Intervention. Edited by Lewis M, Taft LT. New York, SP Medical and Scientific Books, 1982

25. Thomas A, Chess S, Birch HG: The origins of personality. Sci Amer 223:102-109, 1970

26. Plomin R: Heredity and temperament: a comparison of twin data for self-report questionnaires, parental ratings, and objectively assessed behavior. Prog Clin Biol Res 69:269-278, 1981

27. Puig-Antich J: Major depression and conduct disorder in prepuberty. J Amer Acad Child Psychiatry 21:118-128, 1982

28. Rothbart MK: Longitudinal observation of infant temperament. Dev Psychol 22(3):356-365, 1986

29. Matheny AP, Wilson RS, Nuss SM: Toddler temperament: stability across settings and over ages. Child Dev 55:1200-1211, 1984

30. Antonucci TC, Levitt MJ: Early prediction of attachment security: a multivariate approach. Infant Behav Dev 7:1-18, 1984

31. Waters E: The reliability and stability of individual differences in infant-mother attachment. Child Dev 49:483-494, 1978

32. Schneider-Rosen K, Cicchetti D: The relationship between affect and cognition in maltreated infants: quality of attachment and the development of visual selfrecognition. Child Dev 55:648-658, 1984

33. Arend R, Gove F, Sroufe LA: Continuity of individual adaptation from infancy to kindergarten: a reductive study of ego resilience and curiosity in preschoolers. Child Dev 50:950-959, 1979 
34. Egeland B, Farber EA: Infant-mother attachment: factors related to this development and changes over time. Child Dev 55:753-771, 1984

35. Gaensbauer TJ, Harmon RJ, Cytryn L, McKnew D: Social and affective developments in infants with a manic-depressive parent. Amer J Psychiatry 141:223-229, 1984

36. Radke-Yarrow M, Cummings EM, Kuczynski L, Chapman M: Patterns of attachment in two- and three-year-olds in normal families and families with parental depression. Child Dev 56:884-893, 1985

37. Maziade M, Cote R, Boudreault M, Thivierge J, Caperaa P: The New York longitudinal studies' model of temperament: gender differences and demographic correlates in a French-speaking population.J Amer Acad Child Psychiatry 23:582-587, 1984

38. Crockenberg SB: Infant irritability, mother responsiveness, and social support influences on the security of an infant-mother attachment. Child Dev 52:857-865, 1981

39. Darwin C: A biographical sketch of an infant. Mind 2:285-294, 1877

40. Field T, Woodson R, Greenberg R: Discrimination and imitation of facial expression by neonates. Science 218(8):179-181, 1982

41. Freud S: Mourning and melancholia, in The Meaning of Despair. Edited by Gaylin W. New York, Science House, 1968, pp 50-69

42. Robertson J, Bowlby J: Responses of young children to separation from their mothers. Courrier du Centre International de L'enfance 2:131-142, 1952

43. Kaufman IC, Rosenblum LA: Depression in infant monkeys separated from their mothers. Science 155(765): 1030-1031, 1967

44. Poznanski E, Zrull JP: Childhood depression. Arch Gen Psychiatry 23:8-15, 1970

45. Kashani JH, Ray JS, Carlson GA: Depression and depressive-like states in preschoolage children in a child development unit. Amer J Psychiatry 141:1397-1402, 1984

46. Rutter M, Garmezy N: Developmental psychopathology, in Handbook of Child Psychology Vol. 4: Socialization, Personality, and Sexual Development. Edited by Hetherington EM. New York, John Wiley \& Sons, 1983, 776-911

47. Tanguay PE: Towards a new classification of serious psychopathology in children. $J$ Amer Acad Child Psychiatry 23:373-384, 1984

48. Garver DL, Davis JM: Biogenic amine hypotheses of affective disorders. Life Sci 5:383-394, 1979

49. Poznanski E, Mokros HB, Grossman J, Freeman LN: Diagnostic criteria in childhood depression. Amer J Psychiatry 142:1168-1173, 1985

50. Goldsmith HH, Campos JJ: Towards a theory of infant temperament, in The Development of Attachment and Affiliative Systems. Edited by Emde RN, Harmon RJ. New York, Plenum, 1982, pp 161-193

51. Belsky J, Rovine M, Taylor D: The Pennsylvanian infant and family development project, III: The origins of individual differences in infant-mother attachment and infant contributions. Child Dev 55:718-728, 1984 